\title{
Retreatments after multifocal intraocular lens implantation: an analysis
}

\author{
This article was published in the following Dove Press journal: \\ Clinical Ophthalmology \\ I March 2016 \\ Number of times this article has been viewed
}

\author{
Kjell Gunnar Gundersen' \\ Sarah Makari \\ Steffen Ostenstad' \\ Rick Potvin ${ }^{2}$ \\ 'Ifocus Eye Clinic, Haugesund, \\ Norway; ${ }^{2}$ Science in Vision, Akron, \\ NY, USA
}

Gundersen

Ifocus Eye Clinic, Sørhauggaten I I I,

Haugesund 5527, Norway

Tel +4752808900

Email kg@ifocus.no
Correspondence: Kjell Gunnar

Purpose: To determine the incidence and etiology of required retreatment after multifocal intraocular lens (IOL) implantation and to evaluate the methods and clinical outcomes of retreatment. Patients and methods: A retrospective chart review of 416 eyes of 209 patients from one site that underwent uncomplicated cataract surgery with multifocal IOL implantation. Biometry, the IOL, and refractive data were recorded after the original implantation, with the same data recorded after retreatment. Comments related to vision were obtained both before and after retreatment for retreated patients.

Results: The multifocal retreatment rate was $10.8 \%$ (45/416 eyes). The eyes that required retreatment had significantly higher residual refractive astigmatism compared with those who did not require retreatment $(1.21 \pm 0.51 \mathrm{D}$ vs $0.51 \pm 0.39 \mathrm{D}, P<0.01)$. The retreatment rate for the two most commonly implanted primary IOLs, blended bifocal $(10.5 \%, 16 / 152)$ and bilateral trifocal $(6.9 \%, 14 / 202)$ IOLs, was not statistically significantly different $(P=0.12)$. In those requiring retreatment, refractive-related complaints were most common. Retreatment with refractive corneal surgery, in $11 \%$ of the eyes, and piggyback IOLs, in $89 \%$ of the eyes, was similarly successful, improving patient complaints $78 \%$ of the time.

Conclusion: Complaints related to ametropia were the main reasons for retreatment. Residual astigmatism appears to be an important determinant of retreatment rate after multifocal IOL implantation. Retreatment can improve symptoms for a high percentage of patients; a piggyback IOL is a viable retreatment option.

Keywords: piggyback IOL, Sulcoflex, toric, STAAR, symptoms, astigmatism

\section{Introduction}

Multifocal intraocular lens (IOL) implantation has become an increasingly popular choice to reduce spectacle independence at near. ${ }^{1,2}$ While the majority of patients implanted with multifocal IOLs are happy with outcomes, some report being disappointed ${ }^{3,4}$ despite having very good uncorrected visual acuity (VA) ${ }^{3-5}$ Reasons for dissatisfaction after multifocal IOL implantation may include unmet high expectation, ${ }^{6}$ inability to tolerate small residual refractive errors, and visual quality complaints related to the IOL design. ${ }^{5,7}$ Secondary intervention (retreatment) may include corneal refractive surgery, a piggyback lens, or an IOL exchange to correct residual refractive error. Where issues are intractable, the lens may be explanted and replaced with a single-vision IOL. ${ }^{1}$ As the use of multifocal IOLs increases, retreatment cases have also increased. ${ }^{1,8}$

There are a number of surgical and patient factors that can lead to the requirement for retreatment when a multifocal lens is implanted. ${ }^{9}$ Surgical factors include variability in the effective lens position, IOL centration, IOL tilt, and surgically induced astigmatism, all of which may contribute to residual refractive error. ${ }^{1,9}$ Patient factors may include an inability to adapt to the multifocal IOL or a change in the patient's $\mathrm{BY}$
hereby accept the Terms. Non-commercial uses of the work are permitted without any further permission from Dove Medical Press Limited, provided the work is properly attributed. For permission for commercial use of this work, please see paragraphs 4.2 and 5 of our Terms (https://www.dovepress.com/terms.php). 
refraction, ${ }^{1,10}$ ocular health, or pupil size; these factors can reduce the relative perceived effectiveness of the IOL. ${ }^{9}$

Blurred vision (largely due to ametropia), posterior capsule opacification, and photic phenomena due to IOL decentration or large pupils were the most common issues associated with dissatisfaction after multifocal IOL implantation..$^{3,7}$ Contrast sensitivity complaints, glare, and halos have also been commonly reported in multiple studies. ${ }^{2,4,11}$ These phenomena are usually attributed to the fact that multifocal IOL designs split incoming light to provide simultaneous correction of distance and near vision., ${ }^{4,12}$ In the majority of patients, symptoms either improve with time $^{13,14}$ or can be treated successfully., ${ }^{3,15}$

Several studies have examined retreatment rates after multifocal IOLs. Reported rates of enhancement to reduce residual refractive error range from $5.24 \%{ }^{16}$ to $23.66 \%,{ }^{17}$ mostly in the form of laser-assisted in situ keratomileusis (LASIK). ${ }^{13,16,17}$ If symptoms are severe and seem to be related to the multifocal design, then exchanging the multifocal IOL for a monofocal IOL has been suggested. ${ }^{4}$ The reported rate of IOL exchange appears lower, varying from $0.85 \%{ }^{18}$ to $6.98 \%,{ }^{7}$ presumably because exchange may be considered a more invasive option.

A retreatment method is chosen based on the surgeon's perception of the best way to manage the underlying problem. Since refractive error is a common cause of dissatisfaction with a multifocal IOL, a common retreatment modality is corneal refractive surgery. However, corneal refractive surgery may increase the risk of undesirable corneal aberrations ${ }^{12}$ or may be contraindicated in patients with dry eyes - common in cataract patients. ${ }^{10}$ Piggyback IOLs are therefore often employed, especially when there is a large residual refractive error, where there may not be sufficient residual corneal tissue to perform the ablation. ${ }^{1}$ A piggyback IOL is implanted in the sulcus to avoid interlenticular opacification, which was more commonly seen when the piggyback IOL was placed in the bag. ${ }^{19}$

The purpose of this study was to report the retreatment rate after multifocal IOL implantation, including reasons for retreatment, methods used, and clinical outcomes.

\section{Patients and methods}

The local ethics committee the Regional Committees for Medical and Health Research Ethics (REK), Norway reviewed and approved this retrospective chart analysis. The ethics committee did not require patient consent since no patientprotected information outside of surgery dates was collected. All multifocal IOL surgeries performed by a single surgeon at one site in 2013 were identified. Charts for those surgeries considered "uncomplicated" - without surgical complications or comorbidity that might have influenced outcomes - were reviewed. Information related to the original cataract surgery, and any subsequent retreatment, was tabulated for analysis. The tabulated data included preoperative biometry and the original lens implanted, along with postoperative refractive status. For those eyes where a retreatment was performed, similar data were tabulated for the secondary procedure. Subjective impressions of patients who had a retreatment were also collected, both before and after the retreatment.

The primary surgery was performed using a standard protocol for phacoemulsification and small incision surgery (main incision $2.2 \mathrm{~mm}$ ). Secondary surgery for the "piggyback" IOL was performed using the following protocol. One main incision $(2.2 \mathrm{~mm})$ in the steepest axis and two side port incisions $(1.0 \mathrm{~mm})$ located $\pm 60^{\circ}$ from the main incision were made. Standard ophthalmic viscoelastic was used to fill the anterior chamber and open the sulcus. The IOL (Sulcoflex Toric; Rayner Intraocular Lenses Ltd, Worthing, UK) was loaded and injected through the main incision with the haptics placed in the sulcus. In the case of toric lenses, the lens was oriented to the correct axis after the viscoelastic substance had been removed in front of and behind the piggyback IOL. All incisions were hydrated before intracameral antibiotics were instilled as the final surgical step.

There was no retreatment bias. Retreatment was based on the individual patient's desire to improve his or her visual outcomes.

Data were tabulated in Excel, and preliminary data checking and analyses were performed using Access (both Microsoft Corporation, Redmond, WA, USA). Statistical analyses were performed using the STATISTICA data analysis software system, Version 12 (StatSoft, Inc., Tulsa, OK, USA). Statistical testing was performed using analysis of variance (ANOVA) for continuous variables and appropriate nonparametric testing (eg, Fisher's exact test) for categorical variables. Statistical significance was set at level $\alpha=0.05$.

\section{Results}

The chart review identified 416 eyes of 209 patients undergoing uncomplicated multifocal IOL implant surgery in the specified time period. Retreatments were performed on $10.8 \%$ of the eyes (45/416) including $12.4 \%$ of the patients (26/209). Bilateral retreatments were performed in $73 \%$ of cases (19/26). Average time from original implantation to retreatment was 340 days ( $\sim 11$ months), with a range from 6 to 20 months.

There were an approximately equal number of males and females in the database, with no significant difference in the 
retreatment rate by sex (chi-square test, $P=0.6$ ). The average age of patients was $63 \pm 9$ years, with no difference in retreatment rate by age (ANOVA, $P=0.7$ ). The average axial length was statistically significantly higher in the retreatment group (24.19 $\pm 1.23 \mathrm{~mm}$ vs $23.76 \pm 1.25 \mathrm{~mm}, P<0.04)$; the difference was not considered clinically significant. Average keratometry readings were not statistically significantly different between groups $(P=0.95)$. Average corneal astigmatism was slightly higher in the retreatment group $(1.38 \pm 0.99 \mathrm{D})$ relative to the untreated group $(1.02 \pm 1.64 \mathrm{D})$, but the difference was not statistically significant (ANOVA, $P=0.16$ ).

Postoperatively, eyes that required retreatment had statistically significantly higher residual refractive astigmatism than those who did not require retreatment $(1.21 \pm 0.51 \mathrm{D}$ vs $0.51 \pm 0.39 \mathrm{D}, P<0.01)$. Figure 1 shows the distribution of residual cylinder by group. Three quarters (34/45) of the eyes undergoing retreatment had $1.0 \mathrm{D}$ or more of residual cylinder versus $15 \%(56 / 371)$ of the eyes that did not require retreatment. There was no statistically significant difference in the spherical equivalent refractions (SEQ) between the two groups $(P=0.6)$; the distributions of postoperative SEQ were similar between the two groups.

The IOL implanted in the original surgery varied, but the two largest groups accounted for $85 \%$ of the implants;

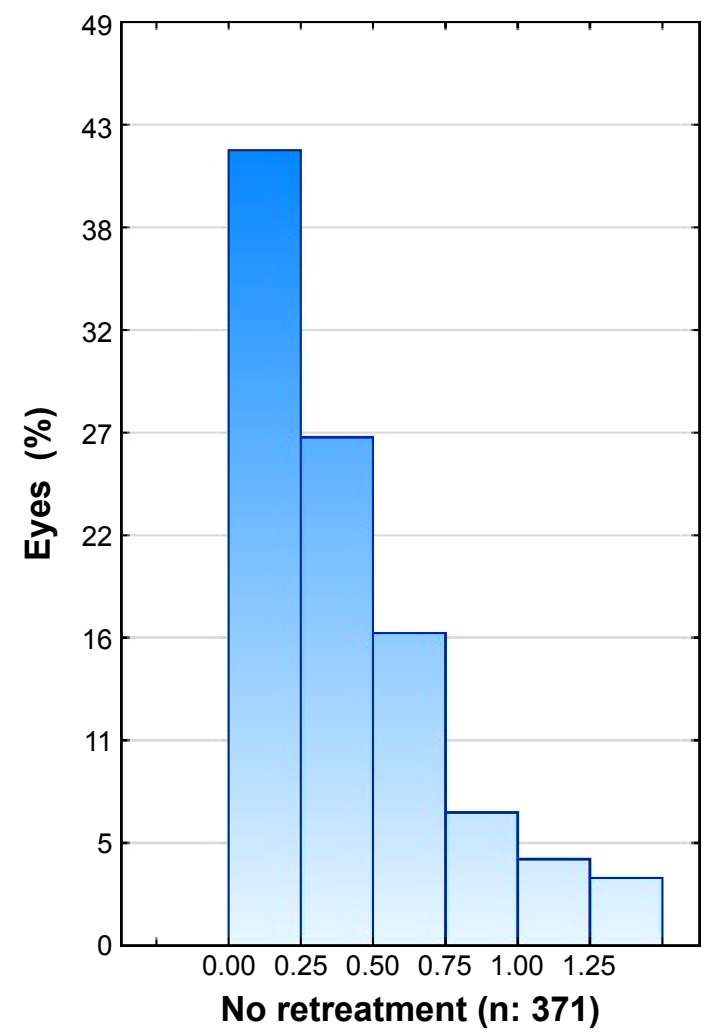

these were patients implanted with bilateral trifocal IOLs ([FineVision; PhysIOL SA, Liège, Belgium], in 202/416 eyes, 49\%) and blended bifocal IOLs (in 152/416 eyes, $37 \%$ ). The blended bifocal IOL included a near bifocal or near bifocal toric lens (SN6AD1 or SND1Tx; Alcon Laboratories, Inc., Fort Worth, TX, USA) in one eye and an intermediate bifocal or intermediate bifocal toric lens (SV25T0 or SV25Tx, Alcon) in the other eye. Both the trifocal and the blended bifocal modalities appeared effective, with retreatments required in 14 of 202 eyes implanted with trifocal IOLs and 16 of 152 eyes implanted with blended bifocal IOLs. The difference between retreatment rates was not statistically significantly different $(P=0.12)$. On average, the blended bifocal group underwent retreatment $\sim 2$ months earlier than those who were implanted with other primary IOLs. The remaining 15 eyes requiring retreatment were originally implanted with an intermediate bifocal (six), an intermediate bifocal toric (two), a near bifocal (six), and a near bifocal toric (one).

Table 1 shows the four retreatment methods and the number of eyes for which follow-up data were missing. All patients receiving corneal refractive surgery noted improvement of their initial complaints. All patients receiving the Collamer piggyback toric IOL (Visian toric ICL ${ }^{\text {TM}}$; STAAR

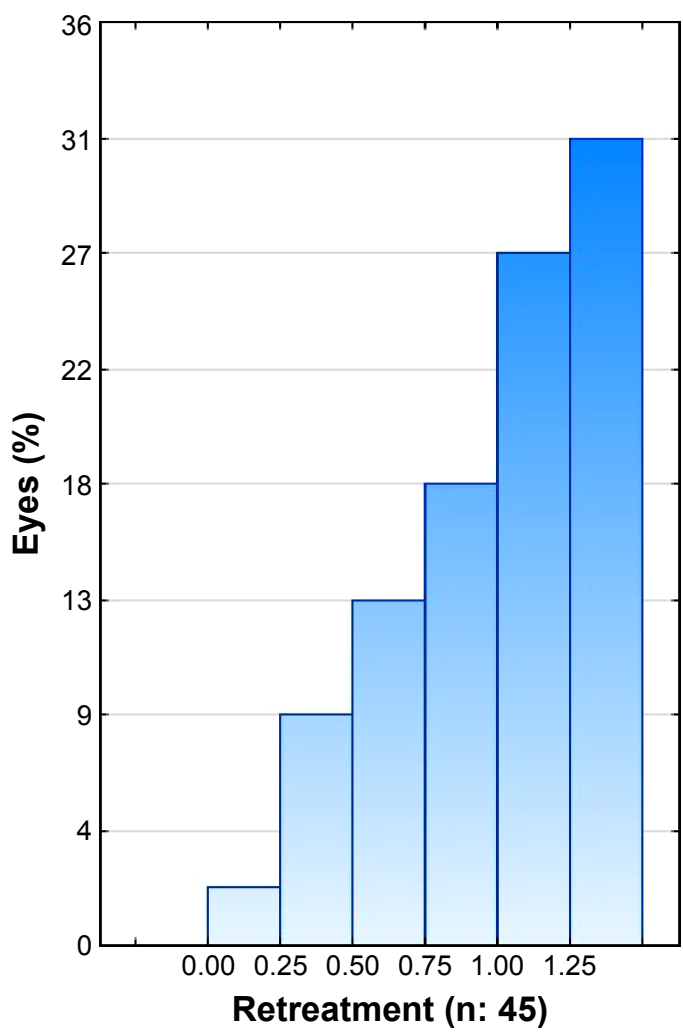

Figure I Postoperative refractive cylinder after original cataract surgery by group (before retreatment where $\mathrm{n}=$ number of eyes). 
Table I Retreatment methods and data limitations

\begin{tabular}{llll}
\hline Retreatment method & Total number of eyes & $\begin{array}{l}\text { Number of eyes with follow-up } \\
<\mathbf{2 9} \text { days }\end{array}$ & $\begin{array}{l}\text { Number of eyes missing visual } \\
\text { acuity data }\end{array}$ \\
\hline Epi-LASIK & 2 (one patient) & 0 & 0 \\
Femto-LASIK & 3 (two patients) & 0 & 0 \\
Piggyback IOL (STAAR) & II (six patients) & 0 & 2 (one patient) \\
Piggyback IOL (Sulcoflex) & 29 (I7 patients) & 5 (three patients) & I (one patient) \\
\hline
\end{tabular}

Abbreviations: LASIK, laser-assisted in situ keratomileusis; IOL, intraocular lens.

Surgical Company Monrovia, CA, USA) had originally been implanted with a bifocal or bifocal toric IOL, and $82 \%(9 / 11)$ of the eyes improved. After implantation with the hydrophobic acrylic piggyback toric IOL (Sulcoflex Toric, Rayner Intraocular Lenses Ltd), 71\% (17/24) of eyes improved. An uncorrected distance VA of 20/25 or better was achieved in $83 \%(19 / 23)$ and $78 \%(7 / 9)$ of the eyes implanted with the Sulcoflex and STAAR toric IOLs, respectively. Results with the different retreatment modalities were not statistically significantly different $(P=0.8)$. All patients receiving piggyback IOLs were implanted with a toric lens due to the presence of refractive astigmatism of $\geq 0.50 \mathrm{D}$. The choice of toric piggyback IOL was arbitrary.

The 26 patients undergoing retreatment provided comments regarding their vision concerns. Table 2 shows all reported issues for eyes/patients before undergoing retreatment. Patient comments were unprompted and categorized here based on specific statements in the text. More than one issue could be reported. The two most common reasons patients elected to undergo retreatment were poor near vision followed by poor distance vision. Near, intermediate, and distance vision issues accounted for $82 \%$ (37/45) of the overall comments. Visual disturbances were less commonly noted. Comments were reviewed and categorized both before and after retreatment. Positive changes were recorded as “improvement".

Table 2 also includes the vision issues reported before and after retreatment in 23 patients (40 eyes); three patients (five eyes) were excluded because only their 1 day postretreatment data were available for analysis. Of these 40 eyes, 31 (78\%) had an apparent improvement in their initial complaints; $78 \%$ of the patients (18/23) reported an improvement. Reported near vision issues significantly decreased, and there were no comments regarding distance vision after retreatment. However, there was a small increase in reported intermediate vision issues after retreatment; a total of four patients (eight eyes) reported them. One of these patients reported difficulty with intermediate vision before retreatment with significant astigmatism in both eyes $(-1.25 \mathrm{DC}$ in one eye and $-2.00 \mathrm{DC}$ in the other eye). After retreatment, this patient noted improvement in intermediate vision with some residual slight haze; the astigmatism was reduced $(-0.5 \mathrm{DC}$ OU), but there was mild residual myopia in one eye ( $-0.50 \mathrm{D}$ SEQ). Two other patients complained of reduced near vision before retreatment and complained of reduced intermediate VA after retreatment. Another patient complained of problems functioning/working before retreatment and problems with intermediate vision after retreatment.

Table 2 Vision issues reported before and after retreatment - more than one issue could be reported (40 eyes of 23 patients had retreatment follow-up $>28$ days)

\begin{tabular}{llll}
\hline Vision issue & $\begin{array}{l}\text { Before retreatment (number of } \\
\text { patients, total =26 patients) }\end{array}$ & $\begin{array}{l}\text { After retreatment (number of } \\
\text { patients, total =23 patients) }\end{array}$ & $\begin{array}{l}\text { Pooled effect of } \\
\text { retreatment }\end{array}$ \\
\hline Near vision & $17^{\mathrm{a}}$ (nine also had distance vision issues) & 3 & $\begin{array}{l}\text { Improved } \\
\text { Distance vision }\end{array}$ \\
I $2^{\mathrm{a}}$ (nine also had near vision issues) & 0 & Improved \\
Not functioning & 3 & 0 & Improved \\
Intermediate vision & $\mathrm{I}$ & 4 & Worsened \\
Not happy & 4 & 3 & $\mathrm{~N} / \mathrm{C}$ \\
Light sensitivity & 2 & $\mathrm{I}$ & $\mathrm{N} / \mathrm{C}$ \\
Lag between the two eyes & 2 & $\mathrm{I}$ & $\mathrm{N} / \mathrm{C}$ \\
Poor visual quality & $2^{\mathrm{a}}$ & 2 & $\mathrm{~N} / \mathrm{C}$ \\
Hazy vision & $\mathrm{I}$ & 2 & $\mathrm{~N} / \mathrm{C}$ \\
Double vision and halos & $\mathrm{I}^{\mathrm{a}}$ & $\mathrm{N} / \mathrm{A}$ & \\
\hline
\end{tabular}

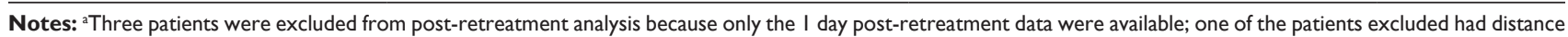
and near vision complaints before retreatment.

Abbreviations: N/A, not applicable; N/C, no change. 
This last patient was implanted with a blended bifocal IOL, and the eye implanted with the intermediate vision IOL was slightly hyperopic (+0.50 D SEQ) before retreatment and ended up myopic ( -1.38 D SEQ) after retreatment.

It is helpful to know if the patient's preoperative complaints are useful in determining success after refractive retreatment with LASIK or piggyback IOLs. Of the 23 patients (40 eyes), 13 patients ( 23 eyes) complained only of refractive-related problems (including distance, near, and/or intermediate VA), seven patients (12 eyes) complained of refractive and other visual disturbances, and three patients (five eyes) complained only of other visual disturbances. When preoperative complaints were only refractive in nature, a larger percentage of patients noted improvement $(85 \%$ or $11 / 13$ vs $70 \%$ or $7 / 10$ ).

Complications were noted in seven eyes after retreatment. One eye of one patient suffered a retinal detachment 6 months after femto-LASIK retreatment, but prior to this, the patient had VA better than 20/20. Another patient had problems with corneal erosion in both eyes but was able to maintain VA better than 20/25 after a Sulcoflex toric (Rayner Intraocular Lenses Ltd) piggyback IOL was implanted. Two patients had lens rotations in both eyes, and both of these patients were implanted with the Sulcoflex toric piggyback IOL. For one of these patients, the lens rotation may have contributed to poor-quality VA. The other patient had lens rotation at the 1 day postoperative, so it is possible that the lens just needed more time to stabilize. No cases of glaucoma, iris chafing, or uveitis have been observed in any retreated eyes to date, and there have been no cases of interlenticular opacification or any hyperopic shift.

\section{Discussion}

In this study, the retreatment rate for multifocal IOL implantation was $10.8 \%$; this falls within the range reported in the literature, although different multifocal IOLs were implanted in earlier studies. ${ }^{16,17}$ There was no statistically significant difference in retreatment rates between the two most common multifocal IOLs implanted in this study. Modern multifocal IOLs share similar optical properties when tested on a bench, although each has a unique pattern for distributing light to far, near, and (for trifocal IOLs) intermediate foci. ${ }^{20}$ Results here suggest that patient factors, particularly residual refractive error, are the most important drivers of the retreatment rate with these lenses.

Available post-retreatment data indicate that retreatment successfully resolved patient concerns in 78\% (31/40) of the eyes; this corresponds well to a study by Woodward et al. ${ }^{7}$
However, intermediate vision complaints persisted in two eyes of one patient and worsened in six eyes of three patients. The patient with persistent reduced intermediate VA had noted improvement after retreatment, most likely as a result of the effective reduction of astigmatism; the low residual myopia in one eye may be the reason for the remaining slight intermediate VA complaints. One patient had a blended bifocal IOL, and the eye treated with the intermediate bifocal IOL had some residual hyperopia prior to retreatment and significant residual myopia after retreatment; this is likely to have negatively impacted post-retreatment intermediate VA. The worsening in the intermediate vision in the other two patients (four eyes) may be a reflection of trying to address their near vision complaints prior to retreatment; this underscores the importance of thorough patient education about the expected visual tradeoffs with multifocal IOLs.

Residual refractive error has been shown to be the most likely reason for dissatisfaction with multifocal IOL implantation ${ }^{6}$ and this also appeared to be the case in this study. Patients with lower preoperative astigmatism were less likely to require retreatment; this result is in agreement with other studies. ${ }^{3,5,7}$ Other potential causes for dissatisfaction with multifocal IOLs that were not evaluated in this study include pupil size, the presence of higher-order aberrations, reduced contrast sensitivity, ${ }^{3}$ and the patient's preoperative refractions; for instance, many appreciate that hyperopes are more likely to be satisfied with multifocal IOLs than myopes. ${ }^{6,13}$

Interestingly, photic phenomenon was a rare complaint reported by the current patient population; this may be a reflection of careful preoperative patient selection. Despite the lower than expected photic phenomena complaints, it may be important to be attentive to other patient complaints before deciding on retreatment options. The results here suggest that if the patient complains only of decreased distance, near, and/or intermediate vision, then a refractive retreatment, such as refractive corneal surgery or piggyback IOLs, may leave the patient with fewer complaints after retreatment. However, if patients have other visual disturbances, with or without refractive complaints, then a more thorough investigation of the symptoms will likely help identify the best retreatment modality for these patients.

The most commonly used retreatment modality in this study was a piggyback IOL. The accuracy of the postoperative refraction, the centration, and stability of the lens are critical in ensuring a successful outcome with piggyback IOLs, especially in patients originally implanted with multifocal IOLs. ${ }^{10}$ Mild decentration of the primary IOL in 
conjunction with a piggyback IOL that is not well aligned with the primary IOL may result in poor visual outcome for patients with multifocal IOLs. ${ }^{21}$

Corneal refractive surgery is also a good retreatment modality though dry eyes are known to increase with increasing age and can increase after cataract surgery with detrimental effects on postoperative outcomes. ${ }^{22-24}$ Injury to the corneal nerve with corneal ablation can produce unfavorable long-lasting ocular symptoms, ${ }^{25}$ further worsening results. For this reason, our primary retreatment modality is a piggyback IOL. We applied the judicious use of corneal ablation as a retreatment after multifocal IOL implantation; corneal refractive surgery was successful when dry eye syndrome was not a concern.

The Collamer piggyback toric IOL (Visian toric ICL ${ }^{\text {TM}}$; STAAR Surgical Company) has been shown to provide good and stable visual outcome. ${ }^{26,27}$ The Sulcoflex lens (Rayner Intraocular Lenses Ltd) is another relatively new piggyback IOL. The Sulcoflex lens has been demonstrated to be safe, predictable, and effective at improving uncorrected distance and near VA. ${ }^{10}$ Both lenses performed the same when used as a retreatment modality in this study.

The complication rate after retreatment was low, attesting to the safety of the most commonly used retreatment modality, the piggyback IOLs or, more specifically, the Sulcoflex toric IOLs. The Sulcoflex toric piggyback IOL exhibited good rotational stability with only one of the 29 eyes implanted having lens rotation that may have impacted visual quality. The good refractive outcomes, stability, and low complication rates reported here with the Sulcoflex toric piggyback IOL are consistent with other studies. ${ }^{10,21}$ No iris chafing or interlenticular opacification have been observed with this lens, during this study or in other patients in practice; this is presumably a function of its design and material properties.

\section{Conclusion}

In conclusion, residual refractive error appears as a common cause of patient symptoms that are sufficient to warrant surgical retreatment. Preoperative astigmatism appears as an important predictor of success with multifocal IOL implantation, although this may be less of a concern with the introduction of multifocal toric IOLs. When necessary, retreatment is effective for a high percentage of patients. This is one of few studies examining the use of the Sulcoflex toric piggyback IOLs in patients originally implanted with multifocal IOLs, results appear promising.

\section{Disclosure}

Richard Potvin is a consultant who reports personal fees from Ifocus Øyeklinikk AS related to this study and outside the submitted work. Sarah Makari, OD, is a consultant who reports personal fees from Science in Vision during the conduct of the study and outside the submitted work. The authors report no other conflicts of interest in this work.

\section{References}

1. Alio JL, Abdelghany AA, Fernández-Buenaga R. Enhancements after cataract surgery. Curr Opin Ophthalmol. 2015;26(1):50-55.

2. Health Quality Ontario. Intraocular lenses for the treatment of agerelated cataracts: an evidence-based analysis. Ont Health Technol Assess Ser. 2009;9(15):1-62.

3. de Vries NE, Webers CA, Touwslager WR, et al. Dissatisfaction after implantation of multifocal intraocular lenses. J Cataract Refract Surg. 2011;37(5):859-865.

4. Kamiya K, Hayashi K, Shimizu K, et al; Survey Working Group of the Japanese Society of Cataract and Refractive Surgery. Multifocal intraocular lens explantation: a case series of 50 eyes. Am J Ophthalmol. 2014;158(2):215-220.

5. Gunvant P, Ablamowicz A, Gollamudi S. Predicting the necessity of LASIK enhancement after cataract surgery in patients with multifocal IOL implantation. Clin Ophthalmol. 2011;5:1281-1285.

6. Blaylock JF, Si Z, Aitchison S, et al. Visual function and change in quality of life after bilateral refractive lens exchange with the ReSTOR multifocal intraocular lens. J Refract Surg. 2008;24(3):265-273.

7. Woodward MA, Randleman JB, Stulting RD. Dissatisfaction after multifocal intraocular lens implantation. J Cataract Refract Surg. 2009; 35(6):992-997.

8. Mamalis N, Brubaker J, Davis D, Espandar L, Werner L. Complications of foldable intraocular lenses requiring explantation or secondary intervention - 2007 survey update. J Cataract Refract Surg. 2008;34(9): 1584-1591.

9. Pepose JS. Maximizing satisfaction with presbyopia-correcting intraocular lenses: the missing links. Am J Ophthalmol. 2008;146(5): 641-648.

10. Venter JA, Oberholster A, Schallhorn SC, Pelouskova M. Piggyback intraocular lens implantation to correct pseudophakic refractive error after segmental multifocal intraocular lens implantation. J Refract Surg. 2014;30(4):234-239.

11. Tassignon MJ, Bartholomeeusen E, Rozema JJ, Jongenelen S, Mathysen DG. Feasibility of multifocal intra-ocular lens exchange and conversion to the bag-in-the-lens implantation. Acta Ophthalmol. 2014;92(3):265-269.

12. Khor WB, Afshari NA. The role of presbyopia-correcting intraocular lenses after laser in situ keratomileusis. Curr Opin Ophthalmol. 2013;24(1):35-40.

13. Altaie R, Ring CP, Morarji J, Patel DV, McGhee CN. Prospective analysis of visual outcomes using apodized, diffractive multifocal intraocular lenses following phacoemulsification for cataract or clear lens extraction. Clin Experiment Ophthalmol. 2012;40(2):148-154.

14. Barisić A, Gabrić N, Dekaris I, Romac I, Bohac M, Jurić B. Comparison of different presbyopia treatments: refractive lens exchange with multifocal intraocular lens implantation versus LASIK monovision. Coll Antropol. 2010;34(suppl 2):S95-S98.

15. Bartholomeeusen E, Rozema J, Tassignon MJ. Outcome after multifocal intraocular lens exchange because of severely impaired quality of vision. Bull Soc Belge Ophtalmol. 2012;319:43-50.

16. Akaishi L, Vaz R, Vilella G, Garcez RC, Tzelikis PF. Visual performance of Tecnis ZM900 diffractive multifocal IOL after 2500 implants: a 3-year follow-up. J Ophthalmol. 2010;2010(pt 2):717591. 
17. Alfonso JF, Fernández-Vega L, Montés-Micó R, Valcárcel B. Femtosecond laser for residual refractive error correction after refractive lens exchange with multifocal intraocular lens implantation. $\mathrm{Am}$ J Ophthalmol. 2008;146(2):244-250.

18. Venter JA, Pelouskova M, Collins BM, Schallhorn SC, Hannan SJ. Visual outcomes and patient satisfaction in 9366 eyes using a refractive segmented multifocal intraocular lens. J Cataract Refract Surg. 2013;39(10):1477-1484.

19. Moshirfar M, McCaughey MV, Santiago-Caban L. Corrective techniques and future directions for treatment of residual refractive error following cataract surgery. Expert Rev Ophthalmol. 2014;9(6):529-537.

20. Carson D, Hill WE, Hong X, Karakelle M. Optical bench performance of AcrySof(®) IQ ReSTOR(®), AT LISA(®) tri, and FineVision(®) intraocular lenses. Clin Ophthalmol. 2014;8:2105-2113.

21. Khan MI, Muhtaseb M. Performance of the sulcoflex piggyback intraocular lens in pseudophakic patients. J Refract Surg. 2011;27(9): 693-696.
22. Moss SE, Klein R, Klein BE. Prevalence of and risk factors for dry eye syndrome. Arch Ophthalmol. 2000;118(9):1264-1268.

23. Kasetsuwan N, Satitpitakul V, Changul T, Jariyakosol S. Incidence and pattern of dry eye after cataract surgery. PLoS One. 2013;8(11): e78657.

24. Movahedan A, Djalilian AR. Cataract surgery in the face of ocular surface disease. Curr Opin Ophthalmol. 2012;23(1):68-72.

25. Levitt AE, Galor A, Weiss JS, et al. Chronic dry eye symptoms after LASIK: parallels and lessons to be learned from other persistent postoperative pain disorders. Mol Pain. 2015;11(1):21.

26. Kojima T, Horai R, Hara S, et al. Correction of residual refractive error in pseudophakic eyes with the use of a secondary piggyback toric implantable Collamer lens. J Refract Surg. 2010;26(10):766-769.

27. Kamiya K, Shimizu K, Kobashi H, Igarashi A, Komatsu M. Three-year follow-up of posterior chamber toric phakic intraocular lens implantation for moderate to high myopic astigmatism. PLoS One. 2013; $8(2): \mathrm{e} 56453$
Clinical Ophthalmology

\section{Publish your work in this journal}

Clinical Ophthalmology is an international, peer-reviewed journa covering all subspecialties within ophthalmology. Key topics include: Optometry; Visual science; Pharmacology and drug therapy in eye diseases; Basic Sciences; Primary and Secondary eye care; Patien Safety and Quality of Care Improvements. This journal is indexed on

Submit your manuscript here: http://www.dovepress.com/clinical-ophthalmology-journal

\section{Dovepress}

PubMed Central and CAS, and is the official journal of The Society of Clinical Ophthalmology (SCO). The manuscript management system is completely online and includes a very quick and fair peer-review system, which is all easy to use. Visit http://www.dovepress.com/ testimonials.php to read real quotes from published authors. 